\title{
Energy use and carbon footprint for potable water and wastewater treatment
}

\author{
Elena PRESURA \\ University POLITEHNICA of Bucharest, Romania \\ Lacramioara Diana ROBESCU \\ University POLITEHNICA of Bucharest, Romania \\ diana.robescu@upb.ro
}

\begin{abstract}
Wastewater treatment plants (WWTPs) and drinking water treatment plants (DWTPs) are sources of emissions of greenhouse gases ( $\mathrm{GHGs}$ ), such as carbon dioxide $\left(\mathrm{CO}_{2}\right)$, nitrous oxide $\left(\mathrm{N}_{2} \mathrm{O}\right)$ and methane $\left(\mathrm{CH}_{4}\right)$. Carbon dioxide emissions have a big contribution to climate change. In general they come from burning fossil fuels to generate the electricity necessary for operating the treatment processes. The demand of energy depends on the treatment processes, but also on the quality of water source or wastewater influent. Water companies have to continuously supply safe drinking water to population and to treat and discharge wastewater according to regulations at a cost as low as possible. In Romania reporting of GHGs is not mandatory for water companies. Evaluation of GHG emissions from water industry have become a subject of great interest because of concern regarding climate change. Research and regulation have been conducted by different authors based on a regional basis. This paper proposes to estimate and compare the carbon emissions resulting from power consumption of Constanta South WWTP and PALAS Constanta DWTP. The energy supplier is different for these plants. In order to calculate the carbon emissions the amount of specific $\mathrm{CO}_{2}$ emissions is determined. The contribution of each primary source to produce the amount of electricity which is consumed is taken into account. WWTP has high power consumption in biological processes, because there are the aeration tanks, the sewage pumping station and the equipment for sludge. DWTP has high power consumption because of the pumping equipment used for raw water abstraction from deep wells and those for drinking water distribution to consumers. In order to identify, sort and display possible causes of the high power consumption of WWTP, Ishikawa chart is used. Through its configuration, the diagram allows highlighting and prioritizing the causes which generate this effect. Some management options are presented in order to reduce power consumption in WWTP.
\end{abstract}

Keywords: carbon footprint, energy consumption, wastewater treatment plant, drinking water treatment plant, management.

\section{Introduction}

Water industry is a potential source for greenhouse gases (GHG) emissions, although GHG emissions levels are not so high as in other sectors. The entire chain of processing water contributes to GHG emissions starting from raw water abstraction, treatment and supply of drinking water, collection and treatment of wastewater and final disposal of the treated wastewater and of the resulted sludge. The main source of carbon emissions is associated with power consumption. With equipment operating 24 hours a day, seven days a week, water and wastewater facilities can be among the largest consumers of energy in a community-and thus among the largest contributors to the community's total GHG emissions, (USEPA, 2013). Due to environmental impact and limited water and energy resources concerns this subject became more and more debated and interesting for researchers. 
There are many studies that have been devoted to this issue. Griffiths-Sattenspiel and Wilson (2009) presented in their report for River Network the energy and carbon emissions embedded in the United States water supplies. They found that at 521 million MWh, water - related energy use is equivalent of $13 \%$ of U.S. electricity consumption and has a carbon footprint of at least 290 million metric tons. Reffold et al (2008), found that the water industry contributes 0.8 per cent of annual UK greenhouse gas emissions. Degrémont and Lyonnaise des Eaux developed a freely accessible web platform to calculate carbon footprint generated by the construction and use of plants in water sector, www.lifecarbontool.com. Bakhshi and deMonsabert (2012), also investigated the energy and emissions associated with municipal water and wastewater service. They showed that it is difficult to model a municipal water system's total energy use and carbon footprint because they are affected by various factors such as the topography, efficiency of water and wastewater treatment, electric utilities etc.

Marín et al (2012), compared different drinking water treatment plants supplying the Barcelona Metropolitan Area, Spain, using Life Cycle Assessment (LCA) of two conventional DWTP and a seawater desalination. Using renewable energies was evaluated to reduce carbon footprint. Biswas and Yek (2016), conducted a LCA analysis on three separate drinking water production options-a groundwater treatment plant, surface water treatment plant and seawater desalination plant. The results revealed that the highest GHGs emissions are from the seawater desalination plant via electrodialysis, while, the groundwater treatment plant has the lowest carbon footprint.

This paper proposes to estimate and compare the carbon emissions resulting from power consumption of Constanta South WWTP and PALAS Constanta DWTP. Only off-site GHCs emissions generated by energy production for WWTP, respectively DWTP supplying is considered. The contribution of each primary source to produce the amount of electricity which is consumed is taken into account.

\section{Wastewater treatment plant Constanta South Site description}

WWTP Constanta South treats $60 \%$ of the domestic and industrial wastewater collected by the combined sewer system of Constanta city, the second largest city of Romania and one of the important international ports. The wastewater treatment process is mechanical-biological one, on two lines: fine and coarse screening, grit and grease removal, primary sedimentation and conventional activated sludge process. The plant is designed for $461000 \mathrm{PE}$, maximum daily flow rate: $276480 \mathrm{~m}^{3} /$ day, hourly flow rate: $3680 \mathrm{l} / \mathrm{s}, \mathrm{BOD}_{5}$ : 31.4 tons/day and TSS: 41.2 tons/day. (Presura and Robescu, 2014).

\section{Carbon emissions resulting from power consumption of Constanta South WWTP}

GHCs emissions from energy consumption of the wastewater treatment system are calculated by quantity of energy used by the WWTP. Electricity in WWTP is need to operate equipment for wastewater and sludge treatment, for administrative building needs and for exterior illumination of the plant.

Power supply of WWTP Constanta Soth is on two medium voltage lines $20 \mathrm{kV}$, which enters the station through a transformation point. From the two lines other five points of transformation are powered. Each point of transformation is provided with two step down 
voltage transformers $20 \mathrm{kV} / 400 \mathrm{~V}$, exception is the main transformer which is provided with other three transformers.

The energy provider for WWTP Constanta South is a private company, S.C. Tinmar-IND S.A. In order to calculate the carbon emissions, the electricity generation sources, Figure 1, and the specific $\mathrm{CO}_{2}$ emissions of 497,21 g/kWh reported for 2013 by this company are considered.

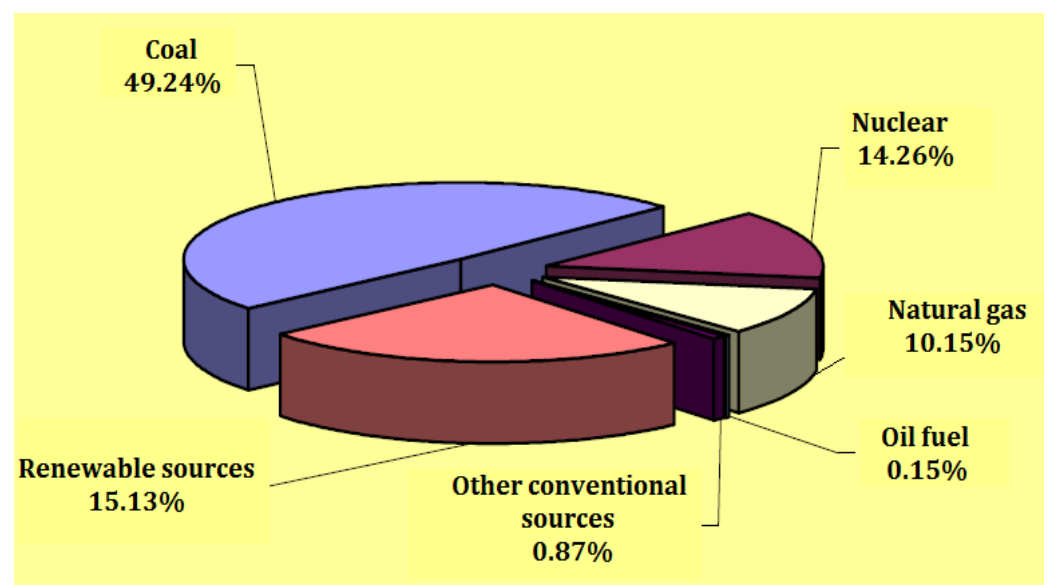

Figure 1. Electricity labeling - SC Tinmar-IND SA

Source: http://www.tinmar.ro/wp-content/uploads/2016/10/Eticheta-Energie-2013.pdf.

Carbon emissions were calculated according to Begak et al., 2013:

$$
\mathrm{CO}_{2}=\text { energy consumption }(\mathrm{kWh}) * 497,21 \frac{\mathrm{gCO}-e}{\text { day }}
$$

resulting $4451.32 \mathrm{~kg} \mathrm{CO}_{2}$-e/day.

In Table 1 it is shown the power consumption of WWTP for 2013 year. It can be seen that the main power consumption is for the wastewater treatment.

Table 1. Power consumptions of WWTP Constanta South

\begin{tabular}{|c|c|c|c|c|c|}
\hline Year & $\begin{array}{c}\text { Power } \\
\text { consumption } \\
\text { [MWh/year] }\end{array}$ & $\begin{array}{c}\text { Wastewater } \\
\text { treatment } \\
\text { [MWh] }\end{array}$ & $\begin{array}{c}\text { Sludge } \\
\text { Treatment } \\
\text { [MWh] }\end{array}$ & $\begin{array}{c}\text { Volume of } \\
\text { wastewater to be } \\
\text { treated } \\
\text { [ } \mathbf{m}^{3} / \text { year] }\end{array}$ & $\begin{array}{c}\text { Volume of } \\
\text { sludge to be } \\
\text { treated } \\
\text { [m } \mathbf{m}^{3} / \text { year] }\end{array}$ \\
\hline 2013 & 4523.437 & 3807.237 & 716.2 & $28,167,304$ & 287,915 \\
\hline
\end{tabular}

Source: SC RAJA SA Constanta.

Power consumption depends on the volume and characteristics of wastewater to be treated, that varies monthly as can be seen from Figure 2 . 


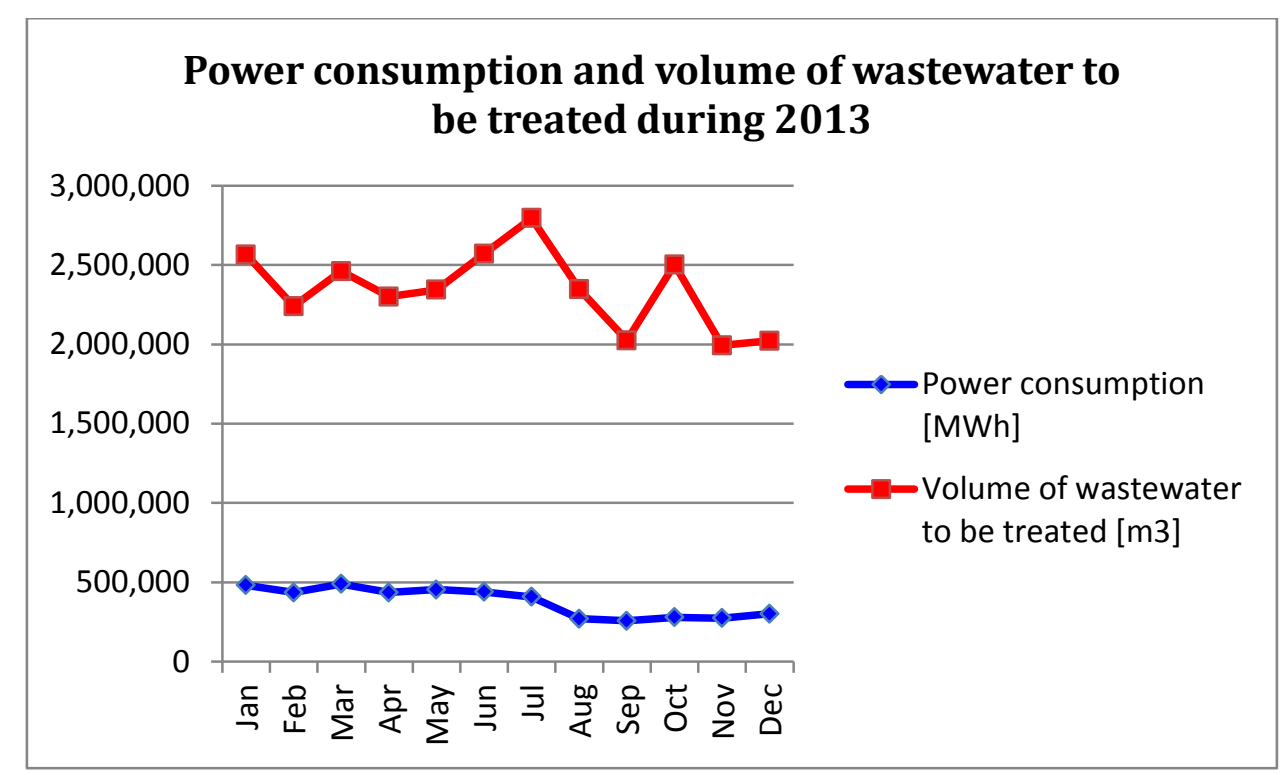

PICBE | 194

Figure 2. Monthly variation of power consumption and volume of wastewater to be treated Source: SC RAJA SA Constanta and authors' research.

Furthermore there are different power consumption for wastewater treatment stages. It can be observed from Figure 3 that the biological treatment has the largest power consumption, because of the aeration. It represents $73.9 \%$ from the total power consumption for wastewater treatment.

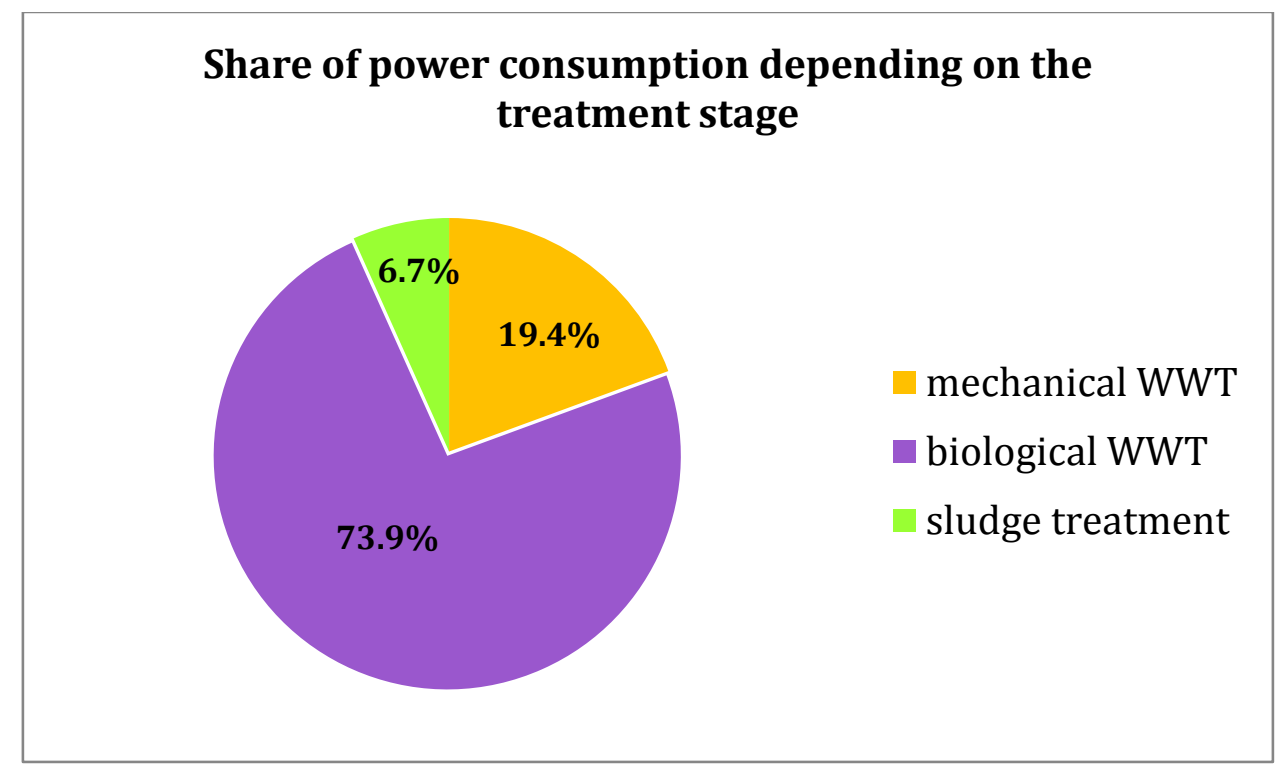

Figure 3. Power consumption share depending on the treatment stage

Source: SC RAJA SA Constanta and authors' research.

Considering the volume of wastewater to be treated, carbon emissions resulted for the treatment of 1 cubic meter of wastewater are $0.0576 \mathrm{~kg} \mathrm{CO}_{2}-\mathrm{e} / \mathrm{m}^{3}$ of wastewater.

In order to identify, sort and display possible causes of the high power consumption of WWTP, Ishikawa chart is used, Figure 4. 


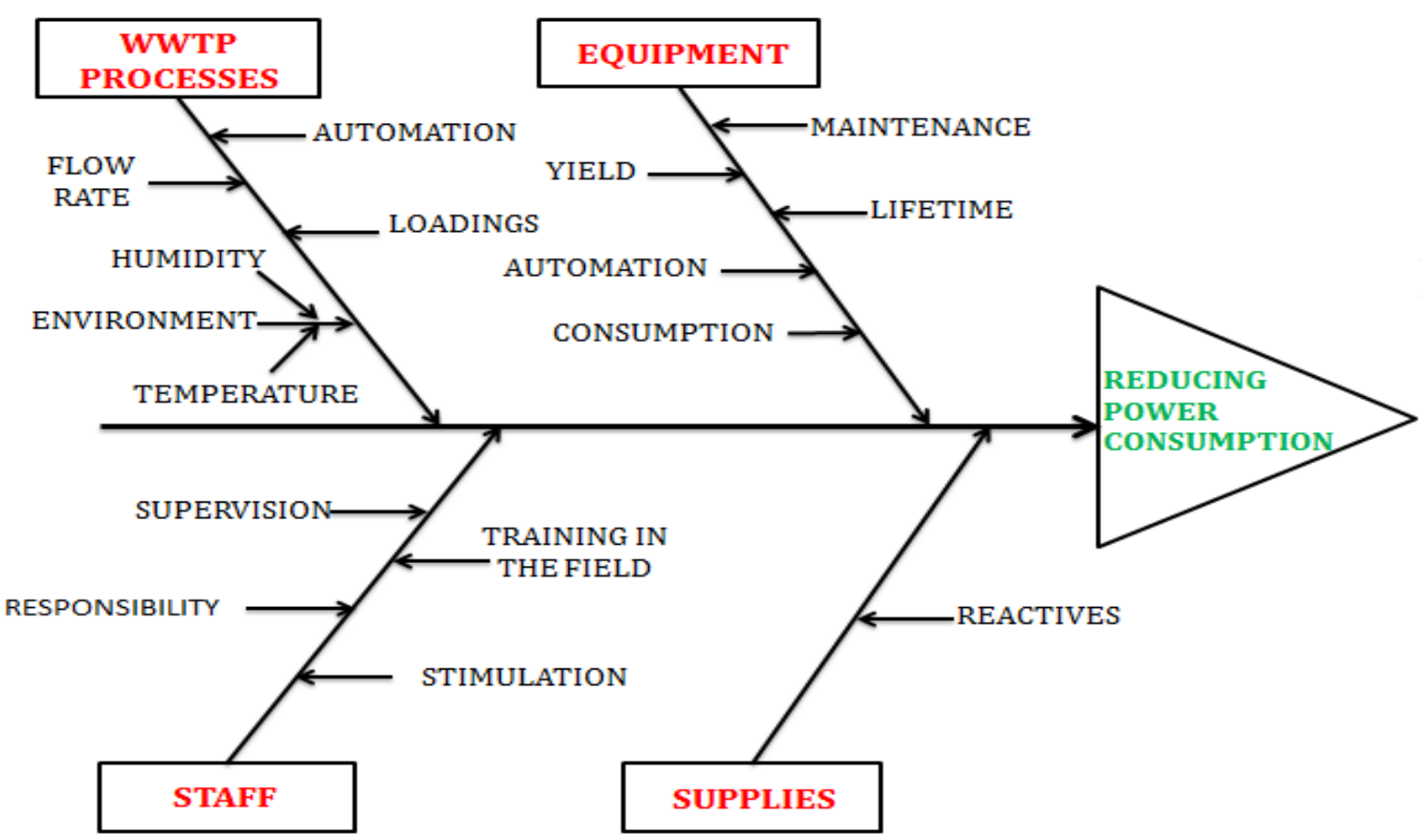

PICBE | 195

Figure 4. Ishikawa diagram for Constanta South WWTP

Source: Authors' own research

Some applicable measures to reduce the power consumption, for each of the main identified causes are presented in Table 2.

Table 2. Applicable measures to reduce power consumption

\begin{tabular}{|c|c|}
\hline Main causes & Applicable measures \\
\hline Equipment & $\begin{array}{l}\text { - Optimizing of plant operation; } \\
\text { - Equipment upgrade - replacing or rehabilitation of old equipment with } \\
\text { new equipment which save energy and has better efficiency; } \\
\text { - Monitoring and control of installations and equipment }\end{array}$ \\
\hline WWT processes & $\begin{array}{l}\text { - Monitoring and control of wastewater treatment processes; Install SCADA } \\
\text { - } \text { Opftware } \\
\text { - Using advanced wastewater treatment for nutrients removal } \\
\text { - UV disinfection } \\
\text { - Using biogas resulted from anaerobic digestion in a cogeneration unit to } \\
\text { - } \quad \text { Using other onsite renewable sources (wind or photovoltaic) }\end{array}$ \\
\hline Supplies & $\begin{array}{l}\text { - Automatic dosing of reagents } \\
\text { - Using efficient reagents }\end{array}$ \\
\hline Staff & $\begin{array}{l}\text { - WWTP staff training in order to update their knowledge regarding } \\
\text { operation of WWT processes and legal provisions related to wastewater } \\
\text { - Training people to better analyze the technical and financial viability of } \\
\text { potential projects; } \\
\text { - Using different stimulation methods }\end{array}$ \\
\hline
\end{tabular}

Source: Authors' research. 


\section{Drinking water treatment plant PALAS Constanta}

\section{Site description}

DWTP PALAS Constanta supplies water for about $2 / 3$ of the area of Constanta city, Navodari and Cumpăna, aproximatively 526000 inhabitants.

There are two raw water sources: Galesu, where surface water is collected and

Cismele, where water is abstracted from deep wells. Most often deep water wells do not need treatment, just disinfection before being distributed to consumers.

\section{Carbon emissions resulting from power consumption of PALAS Constanta DWTP}

$\mathrm{CO}_{2}$ emissions from power consumption of the drinking water treatment system are calculated by energy used by DWTP $(\mathrm{kWh})$. The energy is needed for the pumping equipment used for raw water abstraction from deep wells and those for drinking water distribution to consumers.

DWTP is capturing water from a surface source (Galesu), with a power consumption of $5708128 \mathrm{kWh} /$ year, and from a deep source (Cismele), with a power consumption of $15647061 \mathrm{kWh} /$ year.

In Table 3 it is presented the power consumption for treatment and distribution the water to consumers.

Table 3. Energy consumption of PALAS DWTP Constanta

\begin{tabular}{|c|c|c|c|c|}
\hline \multirow{3}{*}{ Pumping station } & Pumping group & $\begin{array}{c}\text { Working hours } \\
\text { (h/year) }\end{array}$ & $\begin{array}{c}\text { Nominal power } \\
\text { (kW) }\end{array}$ & $\begin{array}{c}\text { Total power } \\
\text { consumption } \\
\text { (kWh/year) }\end{array}$ \\
\hline \multirow{2}{*}{ SP1 } & G1 & 8471 & 160 & 1219824 \\
\cline { 2 - 5 } & G2 & 8684 & 250 & 1953900 \\
\cline { 2 - 5 } & G1 & 8629 & 132 & 1025125 \\
\cline { 2 - 5 } & G2 & 2961 & 132 & 351766 \\
\cline { 2 - 5 } & G3 & 354 & 132 & 42055.2 \\
\cline { 2 - 5 } & G4 & 328 & 132 & 38966.4 \\
\cline { 2 - 5 } & G5 & 2387 & 132 & 283575.6 \\
\hline \multirow{3}{*}{ SP3 } & G1 & 12 & 200 & 8640 \\
\cline { 2 - 5 } & G1 & 48 & 110 & 396 \\
\cline { 2 - 5 } & G2 & 5708 & 110 & 2495092 \\
\cline { 2 - 5 } & G3 & 252 & 110 & 39888 \\
\hline \multirow{3}{*}{ Total } & G4 & 277 & & 5556336.4 \\
\hline
\end{tabular}

Source: SC RAJA SA Constanta.

The total amount of energy used by the DWTP PALAS Constanta is $26911525.4 \mathrm{kWh} /$ year, an average of $73730.206 \mathrm{kWh} /$ day.

Energy provider for DWTP PALAS Constanta is ENEL Dobrogea. Figure 3 presents data regarding energy generation mix for electricity supplied by ENEL Dobrogea.

The annual average of $\mathrm{CO}_{2}$ emission factor for the electricity source reported by ENEL Dobrogea is $302 \mathrm{~g} \mathrm{CO}_{2} / \mathrm{kWh}$. Applying method of Begak et al., 2013, it is obtained $22266.522 \mathrm{~kg} \mathrm{CO}_{2}$-e/day carbon emissions resulted from power consumption of DWTP PALAS Constanta. 


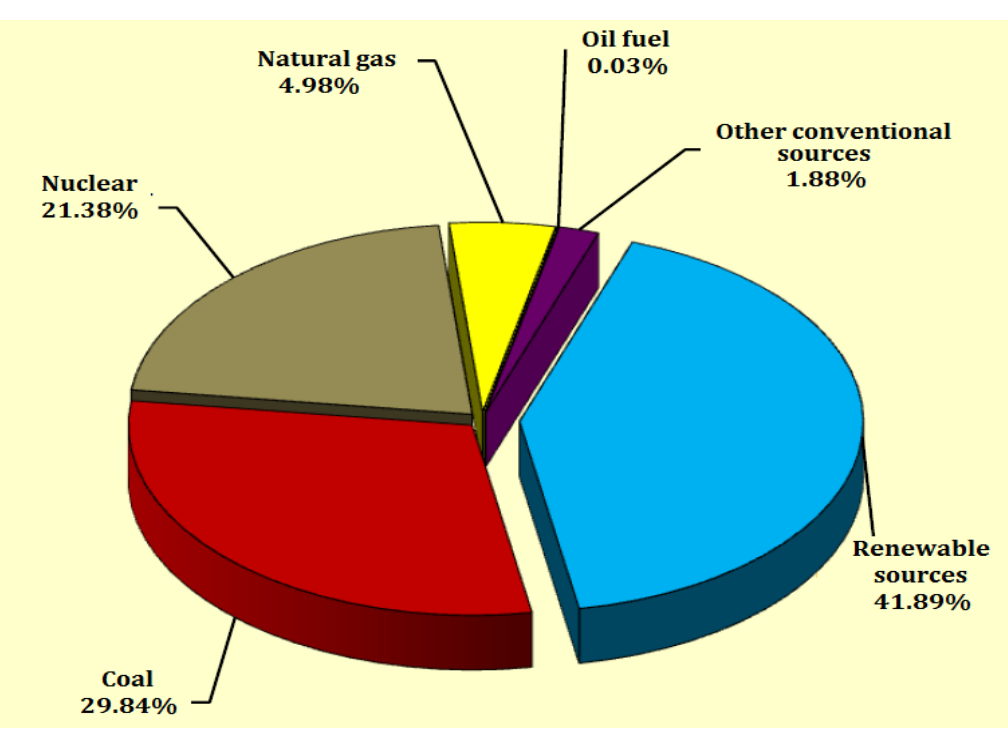

PICBE | 197

Figure 3. Electricity labeling - ENEL Dobrogea

Source: http://www.enel.ro/ro/clienti/lumea/download/Eticheta\%20e.e.\%20-\%20ETR\%202013.pdf.

The average daily flow rate is $162500 \mathrm{~m}^{3} /$ day, so the amount of $\mathrm{CO}_{2}$ emissions for one cubic meter of drinking water is $0.137 \mathrm{~kg} \mathrm{CO} / \mathrm{m}^{3}$ of drinking water.

\section{Conclusion}

The amount of carbon emissions for DWTP PALAS Constanta is $0.137 \mathrm{~kg} \mathrm{CO}_{2} / \mathrm{m}^{3}$ of drinking water and for WWTP Constanta South is $0.0576 \mathrm{~kg} \mathrm{CO} / \mathrm{m}^{3}$ of wastewater. It can be observed that the value for DWTP is bigger than the one of WWTP, even though the annual average of $\mathrm{CO}_{2}$ emission factor for the electricity source reported by energy provider of DWTP is smaller than those reported by energy provider of WWTP. This is because of the pumping equipment used for raw water abstraction from deep wells and those for drinking water distribution to consumers.

Energy use is the main source of carbon emissions in water industry. In dealing with the climate change water companies management should have in view reductions of energy demand that will lead to carbon emissions decreasing. Also renewable sources use and new technologies to recover different products from wastewater and sludge could be considered. Moving to a low-carbon industry is not an easy way. It needs infrastructure and technology implications and consequently financial implications. But, they and all of us should not forget that an important factor is consumers responsibility for using water and for wastewater discharge.

\section{References}

Bakhshi, A.A., de Monsabert, S.M., (2012), Estimating the carbon footprint of the municipal water cycle, Journal - American Water Works Association, 104(5), E337-E347.

Begak M., Guseva T., Molchanova Ya., Averochkin E., Sagaiduk V., (2013), Monitoring and reducing carbon footprint of Russian water and wastewater companies. Methodology for assessing carbon footprint of wastewater treatment plants. On line at: http://14000.ru/projects/carbon-footprint/methodology_eng.pdf. 
Biswas, W.K., Yek, P., (2016), Improving the carbon footprint of water treatment with renewable energy: a Western Australian case study, Renewables: Wind, Water, and Solar, 3:14, online at: https://jrenewables.springeropen.com/articles/10.1186/s40 807-016-0036-2.

Griffiths-Sattenspiel, B., Wilson, W., (2012), The carbon footprint of water, River Network, 2009, online at: https://www.csu.edu/cerc/researchreports/documents/Carbon

PICBE | 198 FootprintofWater-RiverNetwork-2009.pdf.

Marín , D., Juncà, S., Massagué, A., Cortina, J.L., Fonseca, I., Valero, F.,(2012), Impacts on climate change of three drinking water treatment plants supplying Barcelona Metropolitan Area, Proceedings of the IWA Water, Climate and Energy Congress, 1318 May 2012, Dublin, Ireland.

Presura E., Robescu L.D., (2014), Carbon footprint study for a wastewater treatment plant, The Technical-Scientifical Conference "Performance in Water - Sewerage Services", 16-18 iunie 2014, Palatul Parlamentului - Bucuresti, vol. 2, pp. 49-56.

Reffold, E., Leighton, F., Choudhury, F., Rayner, P.S., (2008), Greenhouse gas emissions of water supply and demand management options, Science Report - SC070010, Environment Agency, on line at: www.cost.eu/download/5354.

U.S. EPA, 2013, Energy efficiency in water and wastewater facilities. A guide to developing and implementing greenhouse gas reduction programs, online at: https://www.epa.gov/sites/production/files/2015-08/documents/wastewaterguide.pdf. 